\title{
Agricultural Supply Chain Risk Management in the Post- epidemic Era
}

\author{
Shihua Zeng ${ }^{1, *}$ \\ ${ }^{1}$ Guangzhou College of Technology and Business, Guangzhou, China
}

\begin{abstract}
The COVID-19 has spread in more than 200 countries and regions around the world. China, as the first country to fight the epidemic, took measures such as social isolation, regional blockade, and traffic control, which had a positive effect on preventing the spread of the epidemic, but the agricultural supply chain in the control area received a great impact; in terms of international epidemic prevention, all countries are strengthening their border blockade, safeguarding their own food demand, and strict import and export quarantine measures [1 ], which has a huge impact on the global flow of agricultural products, and the lack of imported agricultural products to supplement the supply security of China's agricultural products is under certain threat. In this paper, by sorting out the paths of the epidemic affecting the supply chain of agricultural products and the characteristics of China's agricultural supply chain, we deeply analyze the sources of risks in China's agricultural supply chain under the epidemic, and put forward suggestions such as strengthening the collaborative management of the agricultural supply chain, building a response mechanism and prevention mechanism for the quality and safety of agricultural products, constructing a logistics network suitable for the storage and transportation requirements of agricultural products, and accelerating the construction of a big data platform for the agricultural supply chain.
\end{abstract}

\section{Introduction}

At the beginning of the COVID-19 outbreak, the Chinese government quickly made a series of policies to combat the epidemic, such as regional traffic control, social quarantine, shutdown of production. The supply chain of agricultural products in the control area was greatly affected, and the entire supply chain of agricultural products production, agricultural products logistics, agricultural products sales, agricultural products import and export were greatly affected, increasing the risk of the agricultural products supply chain [1].

\subsection{Agricultural Production}

Social isolation and shutdown of production may trigger the risk of supply chain breakage. Isolation and shutdown of production lead to agricultural production and processing of agricultural products cannot be continued, and the problem of backlog, decay and stagnation is serious. According to the data released by Wuhan on the economic operation of Wuhan in the first half of 2020, the total output value of agriculture, forestry, animal husbandry and fishery and its service industry in Wuhan is 25.748 billion yuan, which is $18.7 \%$ lower than the same period of the previous year at comparable prices. The city's vegetable output was 3.3659 million tons, down 12.5\%; aquatic product output was 189,800 tons, down $15.2 \%$, which can be seen that the production link of the agricultural product supply chain received a greater impact under the epidemic.

\subsection{Agricultural Products Logistics}

Due to the restrictions of traffic control and the influence of some rural areas directly cut off from road traffic, many logistics delivery lines were temporarily cut off, the lack of distribution personnel, while increasing the links such as express disinfection, the logistics timeliness of major logistics companies were greatly affected.

\subsection{Agricultural Products Sale}

Affected by the epidemic, there is a great uncertainty in the supply and demand of agricultural products, a serious imbalance in supply and demand, and large price fluctuations. Waves of agricultural products are being snapped up all over the country, which also brings greater risks to the stability of the agricultural products supply chain.

\subsection{Import and Export of Agricultural Product}

According to WTO statistics, as of the end of April more than 20 countries have taken restrictive measures on agricultural trade due to the new crown epidemic, among which 12 countries have taken restrictive measures on food exports. On the import side, people's consumption 
enthusiasm under the epidemic received greater inhibition, and the demand for imported agricultural products fell; due to the difference in the effect of epidemic prevention in countries around the world, the supply source of imported agricultural products became unstable; at the same time, some countries took export restriction measures to ensure the security of their basic food supply, which to a certain extent increased the cost of imports and will also inhibit the demand for agricultural imports in China. On the export side, the decline in demand for foreign agricultural products, delayed delivery due to importing countries' control, legal risks, etc. have a greater impact on the export of China's agricultural products.

\section{Characteristics of China's agricultural supply chain under the epidemic}

Agricultural supply chain refers to the whole net strip of agricultural products from production and processing to end consumers. This chain contains agricultural products producers, packaging and processing enterprises, distributors, logistics, end consumers, etc., forming a dynamic and non-linear supply and demand net chain structure [2], as shown in Figure 1. The agricultural product supply chain has significant characteristics such as regional seasonality of production links, high requirements for logistics services in logistics links, and incomplete information in information transfer links, etc. The weak links of the supply chain will be continuously amplified under the epidemic, which increases the potential risks of the agricultural product supply chain.
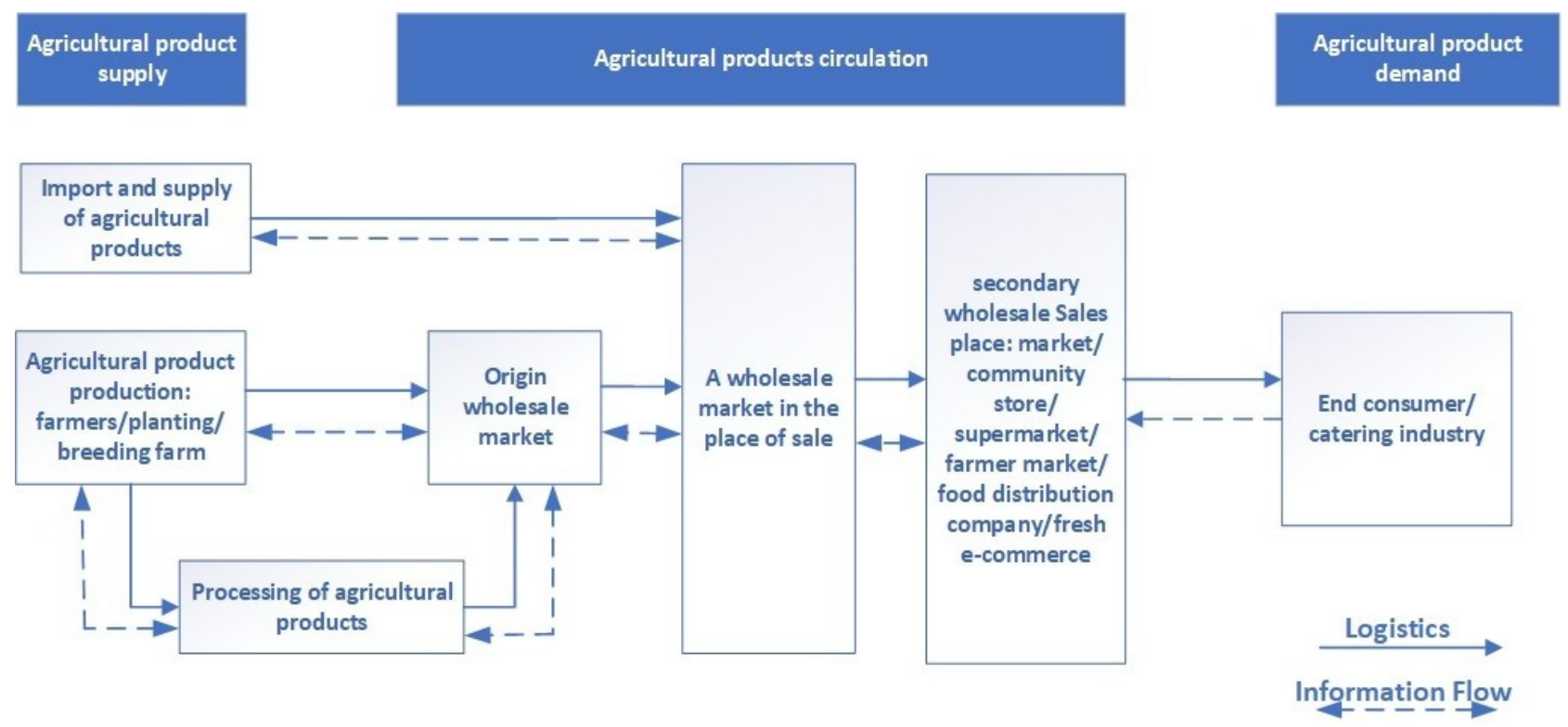

Figure 1 Flow chart of agricultural supply chain organization model

\subsection{The Production of Agricultural Products has Regional and Seasonal Characteristics.}

This characteristic is also significantly amplified under the epidemic. The production of agricultural products in highrisk areas is seriously affected by the epidemic, and policies such as work stoppage, social isolation, and restriction of personnel movement increase labor costs during production and processing, as well as losses in terms of spoilage and deterioration of agricultural products, while concerns about the quality of agricultural products in restricted areas can greatly affect their demand [3-4].

\subsection{The Agricultural Products Supply Chain has High Requirements for Logistics Services.}

Firstly, due to the wide distribution area and scattered nodes, agricultural products require logistics services to lay logistics network in a wider scope; secondly, most of the agricultural products are perishable commodities, which require certain storage and transportation conditions for agricultural products; once again, the low standardization of agricultural products has certain requirements for packaging and transportation of logistics.

\subsection{There is Significant Information Asymmetry and Incompleteness in the Supply Chain of Agricultural Products.}

In the flow chart of Figure 1, the supply market of agricultural products and the demand market of agricultural products are widely scattered, and there is significant information asymmetry in the information transfer link on the status of product price information, supply and demand information, competition and cooperation information and its development trend, and the supply cannot effectively match the demand, which affects the stability of the supply chain. At the same time, the supply chain of agricultural products is relatively long, information transfer is relatively slow and there is incomplete information, coupled with the panic of people under the epidemic, it is easy to form the "bullwhip effect" 
[5]. Under the "bullwhip effect", the production cost of agricultural products rises (overtime, ripening, early harvest yield decline, etc.), the inventory cost of agricultural products rises (responding to fluctuating changes in supply and demand necessarily requires raising inventory), the lead time for replenishment of agricultural products is extended, transportation costs increase, and a series of other problems, which affect the stability and profitability of the supply chain.

\section{Main sources of supply chain risks of agricultural products in China under the epidemic}

According to the different reasons for the formation of risks, there are operational risks, product quality and safety risks, logistics risks, etc. from within the supply chain, as well as external risk factors such as natural risks and market risks in the overall social environment.

\subsection{Internal Operation Risk of Agricultural Supply Chain}

As we can see in the supply chain organization flow chart in Figure 1, the internal operation of the supply chain requires reasonable division of labor, orderly connection and cooperative management of each link in order to improve the efficiency and market competitiveness of the supply chain operation. The production, circulation and sales of agricultural products under the epidemic are subject to different degrees of obstacles. The agricultural products supply chain also has the problem of lacking core enterprises for coordination and organization, and core enterprises play the role of information interaction center and logistics scheduling center in supply chain coordination. At the same time, the resources integrated in the agricultural products supply chain are not sufficient, and more agricultural products resources are strayed from the outside of the supply chain to operate alone, which reduces the overall competitiveness and risk resistance of the supply chain [6].

\subsection{Quality and Safety Risks of the Agricultural Products Supply Chain}

For supply chains related to people's dietary safety, quality and safety risks are often the most deadly, and as people's living standards improve, dietary health and safety are paid more and more attention, and food safety incidents in recent years, such as lean and weak essence of pork, melamine of milk powder, food additives Sudan red, and gutter oil, have become deadly killers in the agricultural products supply chain. The food quality and safety under the epidemic is getting more and more attention, the government's supervision and punishment, the speed of information dissemination in the network era, the quality and safety risks of agricultural products will be wirelessly magnified. Meanwhile, the quality of agricultural products is also a key factor affecting the import and export of agricultural products.

\subsection{The Logistics Risk of Agricultural Products Supply Chain.}

Agricultural products have higher requirements for logistics services. Logistics services under the epidemic have encountered difficulties, not only facing stricter inspection and quarantine, but also transportation has been hindered to a certain extent, and there is a risk of interruption in the logistics delivery of agricultural products in some regions.

\subsection{Natural risk of agricultural products supply chain.}

Agricultural products production is affected by the natural environment, typhoons, droughts, floods, extreme cold are common natural disasters, which will give greatly reduce the supply of agricultural products.

\subsection{Agricultural Products Supply Chain Market Risk.}

The market risk of agricultural supply chain is mainly in the uncertainty of market price and unpredictable market demand, etc. The uncertainty of market price easily makes the production subject suffer losses, and the changeable market demand makes the whole supply chain adjust the production plan. 


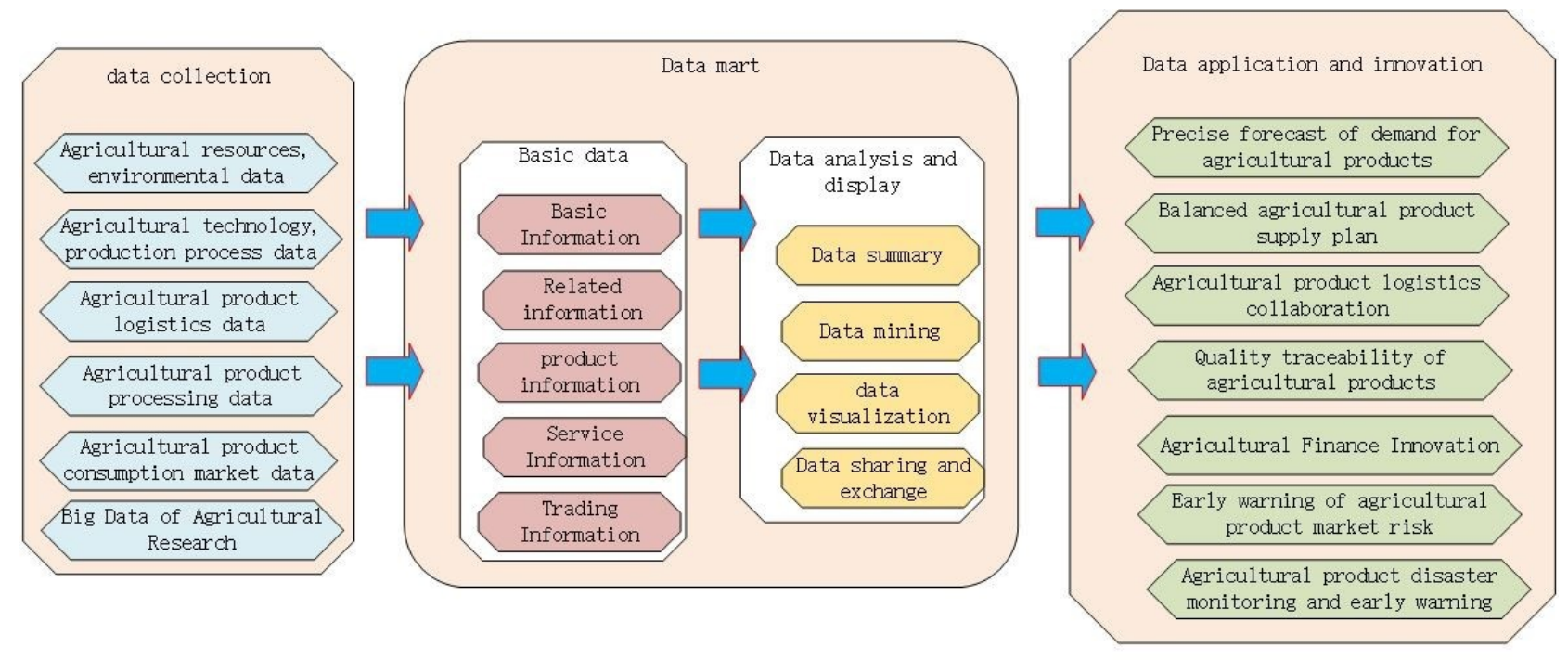

Figure 2 Flow chart of high-efficiency agricultural

\section{Suggestions for risk management strategies for China's agricultural supply chain in the post-epidemic era}

At the beginning of 2021, although the epidemic is getting stronger worldwide, the corresponding vaccine has been developed and put into use, and the experience of epidemic prevention is more mature. The risk management of agricultural products supply chain in the post-epidemic era requires both epidemic prevention and prevention of supply chain risks, avoiding risks according to the causes of risks, establishing risk warning measures and overall preventive measures for major risk factors during the epidemic, focusing on accelerating the construction of big data platform for agricultural products supply chain, vigorously promoting the application of agricultural big data in innovation, and reducing comprehensive risks, as shown in Figure 2.

\subsection{Strengthen the Collaborative Management of Agricultural Products Supply Chain to Reduce Internal Operational Risks}

First, the goal of collaborative agricultural supply chain requires each supply chain member to focus on the total profit of the supply chain rather than their respective share, and the key to collaboration is to establish a mechanism that can generate win-win and risk-sharing. The second is to collaborate on supply chain planning, weaken the bullwhip effect by sharing demand information, and collaborate on forecasting and planning in real time by sharing demand information. Third is to collaborate business processes, supply chain members should use modern information network technology to reorganize business processes, establish advanced business processes in production, procurement, logistics, distribution and sales, etc. to improve the efficiency of supply chain operations.

\subsection{Build Agricultural Quality and Safety Response Mechanism and Prevention Mechanism to Reduce Food Quality and Safety Risks}

First, we should start from the source and strengthen quality and safety publicity and production supervision. The law enforcement and counterfeiting, quality inspection services and legal system and other publicity activities to the front line of agricultural production, to improve the quality and safety awareness of agricultural producers, while the formation of experienced quality and safety supervision team. Second, we must establish a quality and safety of agricultural products risk response. Once the problematic agricultural products are found immediately investigated and controlled to minimize the risk of quality and safety accidents, while the source of the problematic agricultural products should be traced and the person responsible for accountability. Third, we must improve the protection system, and vigorously promote the construction of agricultural market legislation and standardization. Promote agricultural market legislation, regulate the construction and operation of the management system, to create a better business environment and consumption environment for urban and rural residents. Promote the construction of agricultural product standardization, according to the needs of agricultural product quality and safety supervision, in accordance with the principle of matching pre-production, production and post-production standards, actively adopt international standards, promptly clean up and revise outdated agricultural national standards and industry standards, and urgently develop the much-needed agricultural product quality and safety standards [7]. Fourth, strengthen the management of imported agricultural products to prevent the risk of importing epidemics. The foreign epidemic situation is not optimistic, to prevent the risk of epidemic through the import of cold chain food, strengthen the management of imported agricultural products inspection and quarantine. 


\subsection{Construct a Logistics Network Suitable for the Storage and Transportation Requirements of Agricultural Products to Reduce Logistics Risks}

To build a logistics network suitable for storage and transportation of agricultural products, one is to strengthen the logistics of "the first kilometer" and "the last kilometer" storage and transportation conditions, "the first kilometer" refers to the pre-chilling treatment of agricultural products from picking The "first kilometer" refers to the pre-cooling treatment of agricultural products from picking to transportation, and empirical studies have found that proper treatment of the "first kilometer" can greatly improve the shelf life and freshness of commodities. The "last kilometer" refers to the ability to complete the delivery within half an hour or one hour after the order is placed. Second, we should vigorously develop and adopt all kinds of cold chain transportation tools and develop multi-functional, different scale and multitemperature cold storage, which are the core of modern cold chain transportation system. Third, the processing workshop should be equipped with temperature control devices, so that the processing of agricultural products will not deteriorate due to changes in external climatic conditions.

\subsection{Speed up the Construction of Big data Platform of Agricultural Products Supply Chain to Reduce the Comprehensive Risk}

Accelerating the construction of big data platform of agricultural products supply chain, provide supply chain related agricultural information, price quotation, difficult to sell promotion, regional agricultural products and other information, improve the information level of agricultural products supply chain, promote the efficient application of big data in the whole agricultural supply chain and innovation, which can reduce the overall risk of supply chain as shown in Figure 2. Accelerating the construction of big data platform for agricultural product supply chain, one is to strengthen the information procurement of the whole agricultural supply chain links, such as Agricultural resources, environmental data, Agricultural technology, production process data Agricultural product logistics data, Agricultural product processing data, Agricultural product consumption market data, Big Data of Agricultural Research and other data collection. Secondly, we should improve the storage and analysis of basic data, aggregated data and derived data of agricultural supply chain, and do a good job of analysis, mining, visualization, information sharing and exchange of big data of agricultural product supply chain. Third, we should strengthen the application and innovation of agricultural supply chain big data, such as in precise forecast of demand for agricultural products, balanced agricultural product supply plan, agricultural product logistics collaboration, quality traceability of agricultural products, agricultural finance innovation, early warning of agricultural product market risk, agricultural product disaster monitoring and early warning.

\section{Conclusion}

This paper has conducted a more in-depth analysis of the path of the epidemic affecting the agricultural supply chain, the characteristics of China's agricultural supply chain and the sources of risks in China's agricultural supply chain, and studied the risk management strategies of China's agricultural supply chain in the post-epidemic era. In the post-epidemic era, the epidemic has farreaching effects on the economy, society, politics and $\mathrm{w}$ of various countries and is still continuing, increasing the uncertainty in various aspects of the agricultural supply chain. The construction of risk management strategies for China's agricultural supply chain in the post-epidemic era is forward-looking to ensure the safety and stability of the agricultural supply chain.

\section{References}

1. W. Wang, "Collaborative information management in agricultural products supply chain in China: A case study of Wumart," The 26th Chinese Control and Decision Conference (2014 CCDC), Changsha, China, 2014, pp. 3590-3595.

2. L. Xuemei, "Study on the Agricultural Products Supply Chain Risk Based on Internet of Things Environment," 2015 8th International Conference on Intelligent Computation Technology and Automation (ICICTA), Nanchang, China, 2015, pp. 875-877.

3. Yang Fang, "Research on operation mode of Jiangxi green agricultural products closed supply chain," 2011 International Conference on New Technology of Agricultural, Zibo, China, 2011, pp. 626-629.

4. Wang Yindi and Lan Hongjie, "Fresh agricultural products supply chain in the e-commerce environment vulnerability model," 2015 International Conference on Logistics, Informatics and Service Sciences (LISS), Barcelona, Spain, 2015, pp. 1-4.

5. L. Wang, X. Sun and H. Wang, "Grey-game in agricultural perishable products supply chain under union," 2010 IEEE International Conference on Automation and Logistics, Hong Kong, China, 2010, pp. 82-87.

6. G. Li and S. Yu, "Study on construction of agricultural product supply chain and benefit distribution based on agricultural industrialization poverty relief project: Taking Rosa sterilis processing industry as the example," 2017 International Conference on Service Systems and Service Management, Dalian, 2017, pp. 1-3.

7. A. Villalva-Cataño, E. Ramos-Palomino, K. Provost and E. Casal, "A Model in Agri-Food Supply Chain Costing Using ABC Costing: An Empirical Research for Peruvian Coffee Supply Chain," 2019 7th International Engineering, Sciences and Technology Conference (IESTEC), Panama, Panama, 2019, pp. 16. 